\title{
Editorial
}

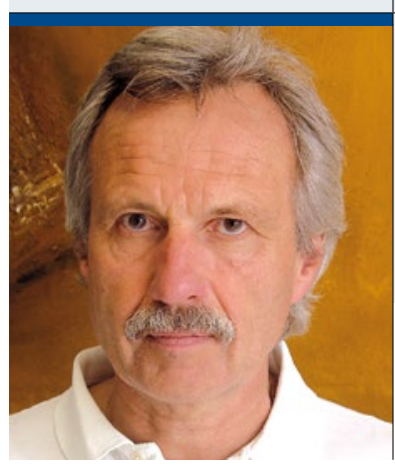

"Krankenkassen und Ärzte bezichtigen sich traditionell

gegenseitig der manipulierten Umleitung von Kaufkraft auf

die eigenen Konten."

\section{Cosa medica nostra?}

$\mathrm{D}$ ie Nachrichten der letzten Zeit lesen sich wie Mitteilungen über die „ehrenwerte Gesellschaft". Der Kojak-Verschnitt und frühere KV-Chef steckt sich in die Tasche, was er braucht und nicht was ihm gehört („Ist doch entzückend, Baby!“). Krankenkassen und Ärzte bezichtigen sich traditionell gegenseitig der manipulierten Umleitung von Kaufkraft auf die eigenen Konten. Tun dies die Ärzte, bezichtigen die Krankenkassen sie des Betrugs und es wird umgehend nach dem Staatsanwalt gerufen. Tun es die Kassen und bezahlen den Ärzten erbrachte Leistungen nicht, ist das normal und nicht rechtswidrig. Rufen die Ärzte Justitia an, beruft diese sich auf Sehverlust und der Staatsanwalt findet die Robe nicht. Interessant wird es, wenn sich die Krankenkassen gegenseitig und das Gesundheitssystem als solches betrügen. Das nennt man dann "schummeln“, Optimierung der Codierung (FAZ v. 9.10.16) oder, intellektuell verfeinert, „upcoding“"

Der TK-Chef Jens Baas brachte es in die Medien: Alle Kassen und allen voran angeblich die AOK möchten ihre Versicherungsnehmer morbider aussehen lassen als sie es sind, um mehr Geld aus dem Fonds für den Risikostrukturausgleich (RSA) zu erhalten. Damit hat der chirurgische Kollege Baas einen tiefen Schnitt gesetzt und einen grollenden Aufschrei aller beteiligten Pharisäer provoziert. Die AOK sieht „Ärzte, Aufsichten und Krankenkassen“ diffamiert. Erstaunlich, dass die AOK auch die Ärzte einbezieht. Nehmen Krankenkassen nämlich Ärzte in Schutz, ist Vorsicht geboten. Zur Rechenschaft gezogen, werden die Kassen die Ärzte der Falschcodierung bezichtigen - und natürlich des Betrugs. Herr Gassen (KBV) baut vor: „Ärzte sehen sich von manchen Krankenkassen unter Druck gesetzt, bestimmte Codierungen doch häufiger vorzunehmen“. Machen Kassen etwa Vorschläge, die Ärzte nicht ablehnen können?

Der Spitzenverband der GKV hat die Schuldfrage ohnehin schon gelöst: Die Einführung verbindlicher Richtlinien für Diagnosen sei von der Ärzte- schaft boykottiert worden. Umgehend plädiert der BÄK-Präsident denn auch für eine rasche Aufklärung der Manipulation und nur der Hartmannbund lobt den Vorstoß des TK-Chefs als ,wichtig und mutig".

Vor allem fürchten $\mathrm{AOK}$ et al. aber um den $\mathrm{Zu}$ fluss von Talern aus dem RSA und finden bei den SPD-Genossen Rückhalt. Deren gesundheitspolitische Sprecherin betont, dass der RSA weiterentwickelt werden müsse und nur von denjenigen kritisiert werde „die sich als Einzahler sehen“.

Die „Stiftung Patientenschutz“ stellt Strafanzeige gegen die TK. Das ist grotesk, bedenkt man, wie diese angeblich Schutzbedürftigen völlig ungehemmt aggravierend ein ,upcoding“ zu ergaukeln suchen, wenn es um den gewünschten Grad der Behinderung (GdB) geht oder die Durchsetzung einer vorzeitigen Alters- oder EU-Rente. Da wäre eine Strafanzeige ebenfalls angebracht.

Das Bundesversicherungsamt ist auch erwacht und will zunächst die TK prüfen. So trachtet die Revolution mal wieder ihren Kindern nach dem Leben. Ob jetzt Minister Gröhe das Dauergrinsen vergeht?

Wie auch immer, der Dagobert Duck 'schen Lust am Horten von Zahlungsmitteln im hauseigenen Tresor scheint niemand widerstehen zu können. Vielleicht öffnen sich ja zu dem bevorstehenden Weihnachtsfest die Tresortüren. „Anstatt immer nur das Beste geben zu wollen, sollten wir lieber einmal etwas Gutes tun" (Peter Ustinov).

Frohe Festtage - und bleiben Sie uns auch 2017 gewogen

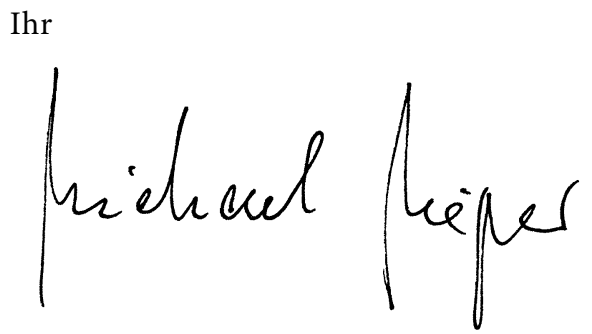

